\title{
"HER BODY, HER RIGHT"?: INTERROGATING THE DISCOURSE ON ABORTION IN SRI LANKA*
}

\section{CARMEN WICKRAMAGAMAGE}

\begin{abstract}
This paper calls attention to an issuc, abortion, that requires the urgent attention of those interested in the reproductive health indicators of women. The author's investigation of the issue arises from three particular phenomena: a) the high incidence of back-alley abortions in Sri Lanka; b) the failed attempt in 1995 by the People's Alliance government to liberalise the restrictive law on abortion; and c) the media campaign of the Women's NGO Forum in 1999 to generated a public debate on the issue. The paper begins with an analysis of both how and why abortion has come to be such a key issue in discussions on and debates around women's rights and women's reproductive health across the globe and argues for considering it a vital reproductive health issuc in Sri Lanka as well. It then critically interrogates the vocabulary deployed by the Women's NGO Forum to initiate a debate in Sri Lanka and proposes an alternative grammar of communication that might better suit the particular socio-cultural context and better address the issues at hand.
\end{abstract}

This paper offers theoretical interventions into an issuc, abortion, that requires the urgent attention and intervention of all policy planners, family planning service providers, health care professionals, and women's rights activists interested in the reproductive health indicators of women. My reflections on and interrogation of the Abortion Question arise from three particular phenomena: a) the reportedly high incidence of back-alley (i.e., illegal) abortions in Sri Lanka; b) the absence of political will among Sri Lankan parliamentarians as demonstrated in 1995 when they failed to make even minimal amendments to the archaic, $19^{\text {th }}$ century, law on abortion to bring it into line with present day realities; c) the attempts by the Women's NGO Forum in 1999 to generate a debate on the Abortion Question through the media, i.e., a television and newspaper, campaign.

\footnotetext{
- This is a substantially revised version of a paper prescnted at the seventh National Convention on Women's Studies, held from 23-26 March 2000, at CENWOR, Colombo.
} 
Both official and unofficial sources in recent times have been quoting figures in the range of five hundred to one thousand as a rough estimate of the number of illicit abortions performed a day - an extremely high number, whether the number is seen as a ratio of the (reproductive age group) female population in Sri Lanka or in comparison with internationally available data. ${ }^{1}$ Such a high number also raises concerns regarding the toll on the reproductive health of women undergoing these back-alley abortions, mostly performed by people who pay little heed to health concerns. ${ }^{2}$ Moreover the high numbers clearly demonstrate that the continued criminalisation of induced abortion through an 1883 law (Article 303 of the Penal Code enacted in 1883) has not stopped the practice. But the reluctance in 1995 of the Ministry of Justice to amend the law so as to make abortion legally available $a t$ least in the cases of rape and incest, as well as the impassioned debate in Parliament on the issue, signify the presence of religio-cultural orthodoxies that oppose abortion on principled grounds. ${ }^{3}$ The intervention by the Women's NGO Forum in the form of an advertisement campaign in 1999 might therefore be seen as an attemapt to draw attention to an issue that requires urgent attention but is in danger of becoming a non-issue. ${ }^{4}$ However, even the NGO Forum's provocatively worded message, "Her Body, Her Right," calling for a more liberal law on abortion, has so far failed to elicit a response from or generate a debate among concerned individuals and parties. ${ }^{5}$ This failure to generate a debate suggests an indifference that is untenable considering the high number of illicit abortions performed, the number of hospital admissions arising from abortion-related complications, and the percentage of maternal deaths that are officially recorded as due to abortion. ${ }^{6}$ This paper therefore critically interrogates, on the one hand, the vocabulary deployed by the NGO Forum to initiate the debate, which the author argues is problematic. It proposes, on the other hand, an alternative grammar of communication that might better address the issues at hand - one that the author hopes will resonate more positively within the Sri Lankan socio-cultural, economic, and political contexts. 


\section{BACKGROUND}

The practice of abortion is not new. It is the discourse on abortion that is. The discourse on abortion in its present form began to emerge in the 1960s, either within a framework of women's reproductive or human rights, or as part of the new politics of population. In most western countries, the liberalisation of abortion law was an integral part of the demand for female autonomy - in sexual as well as in all other matters - that fueled the second-wave women's movement of the ' $60 \mathrm{~s}$ and '70s. The United Kingdom was the first country to relax its law in 1968, followed soon after by the United States in 1973 and most other western European states in the 1970s and '80s. In Eastern Europe, or the former Socialist Bloc, while there was no autonomous women's movement as such to demand the right to abortion as part of a woman's right to sexual decision-making, abortion services were made available in state hospitals for "public health reasons" (Tribe 1992:57).

It is in the so-called developing world that liberalisation of the abortion law has come to be tied to a "new politics of population" - a new politics that separates national might from population size and in fact begins to view population increase as detrimental to social and economic development agendas. India and China, the world's two most populous nation-states, were the first to relax abortion laws as a means to decelerate population growth. ${ }^{7}$ So the Indian Medical Termination of Pregnancy (MTP) Act, introduced in 1972 to permit abortion under medical supervision, has always been perceived as a "a tool of population control" that had nothing to do with reproductive freedom for women (Gupte, Bandewar and Pisal 1997:77). In the case of China, the liberalisation of the abortion law, linked as it is to state policy on onechild per family, has only led to a gross erosion in human rights - with couples forced to abort where they already have one child and others resorting to aborting or killing female foetuses or children because of traditional son preferences (Tribe 1992:62-63). Today, even Bangladesh and Indonesia, both Islamic countries, permit "menstrual regulation" under which euphemism abortions too can be performed in the early months with no questions asked (Crane 1994: 249). 
Sri Lanka is, in a way, a latecomer to the transnational discourse on abortion. There had been no pressing need to initiate or develop a discourse on abortion in Sri Lanka, in line with the still-evolving discourse on abortion internationally, because Sri Lanka did not have to resort to abortion as a method of population control, the main reason why a more permissive legal and social climate for induced abortion emerges in many developing countries. Along with India, Sri Lanka was among the first developing countries in the world to recognize unplanned population increase as a problem and the need for state intervention to curb population growth (Finkle and McIntosh 1994:3). In Sri Lanka's case, an aggressive family planning campaign through the 1960s and 1970s, emphasizing the benefits of smaller family size and popularising artificial contraceptives as the means for birth control, has paid high dividends. The total fertility rate, which was 5.3 in the 1950 s, has seen a dramatic reduction to 2.3 by the 1990 s. Thus, both government interest in and commitment to family planning, and timely international donor commitment (Swedish, in this instance), have enabled Sri Lanka to achieve a drastic reduction in growth rates through pregnancy prevention rather than pregnancy termination. ${ }^{8}$

However, official disinterest in induced abortion as a means of birth/population control has not necessarily quashed the interest of the populace in induced abortion as a means of birth prevention. ${ }^{9}$ And this phenomenon is not peculiar to Sri Lanka. As Barbara Crane points out, "induced abortion has been practiced throughout history, even in cultures where prevailing norms have opposed it. During the demographic transition to lower fertility, population specialists suggest that either abortion alone, or both abortion and contraception, tend to increase for a time until eventually contraceptive practice improves, and resort to abortion declines, although it is never eliminated" (1994: 257). The high numbers quoted by both official and unofficial sources suggest that the government's desire and decision to achieve lower fertility rates through contraception alone has not worked. Profiles of abortion seekers made available through research and observations of health care professionals in fact suggest that a high percentage of married women too resort to abortion as a means of birth delaying, birth spacing and birth prevention (Sirisena 1991: 4-5; Hewage 1994: 326). There is 
no hard evidence, in the case of Sri Lanka, that the dramatic reductions in fertility rates were always partially made possible through abortion. Some researchers point to more recent "life-style changes" (Ariyaratne 2001:41) employment opportunities for women in the Middle-East and in the local labour market at the lower end of the economic spectrum, for instance - as reasons for resort to abortion as a means of pregnancy termination and birth prevention. Whatever the specific reasons for the high incidence of abortion in Sri Lanka, it is a fact that illicit abortion remains a highly sought-after service in Sri Lanka. It is also a fact that some percentage of maternal mortality and morbidity could be attributed to abortion although the very criminalisation of abortion perhaps prevents effective monitoring and recording of links between illicit abortion and medical complications. ${ }^{10}$

There is then a pressing need to review the present legal and social status of abortion in Sri Lanka. Internationally, numerous conferences, charters and conventions in recent years have made reference to unsafe abortion as a practice that diminishes women's life-chances. A transnational discourse on human rights has stressed the right to life and health as a fundamental human right and feminist and health care advocates have sought to include a right to reproductive health, that is, "access to services that will ensure safe pregnancy and childbirth" (de Silva 2001: 49), as a woman's inalienable human right. Pro-Choice groups everywhere would also like to include a right to safe and cheap abortion services, in a climate free from intimidation and shame, as part of the reproductive health rights of women (Crane 1994: 255). The target set by the Safe Motherhood Conference (Nairobi, 1990) was a $50 \%$ reduction by the year 2000 of the 1990 levels of maternal mortality rates. While the International Conference on Population and Development (Cairo, 1994) refused to name or accept abortion as part of women's reproductive rights due to intense lobbying by a transnational coalition opposed to abortion, it drew attention to the need to reduce maternal mortality (de Silva 2001:49) and acknowledged abortion as "a major public health problem" (Berer 1997:6). However, the Fourth World Conference on Women (Beijing, 1995) made women's reproductive rights an important plank in their platform for action. More recently, the Safe Motherhood Technical Consultation (Colombo, 
1997) "placed maternal mortality in the context of human rights and urged governments to fulfill the obligations they have undertaken by endorsing and ratifying the various international human rights instruments" (de Silva 2001: 49).

In Sri Lanka, while official state policies on health, family planning or population make no reference to induced abortion as either a health issue or a tool for population control, the Women's Charter (1993) ratified in Parliament “includes a reference to women's right to control their reproductive function" (Abeyesekera 1997:87). And this "right" includes the right for women to decide if and when they wish to get pregnant. However, in a situation where induced abortions are not only socially unacceptable but also (mostly) criminal under the law, a right to reproductive health, that is, safety, takes precedence over the right to reproductive autonomy. As Sirisena(1991:1), a health care professional points out, most clandestine abortions are performed in unhygienic conditions by service providers who do not possess the requisite training or equipment to perform the procedure safely. Most such clandestine service providers do so for money and pay very little heed to the short-term and long-term health implications of the procedure on the service seekers. Thus, if abortion is "unsafe" in Sri Lanka, its "unsafe" nature is the result of the legal and social climate that surrounds the practice of abortion. As Hewage points out, "safety of abortion depends mainly on the stage of gestation and the skill of the provider. Because abortion is illegal and because of the socio-cultural climate, many women may go to unqualified providers and wait longer" (1994: 327). A new discourse on abortion is then necessary to influence opinion and law-makers towards a more permissive social and legal climate towards abortion.

\section{THE ISSUES AT STAKE}

Liberty vs. Life are the seemingly irreconcilable opposites that fuel the debate over abortion internationally. Harvard Law professor, Lawrence Tribe, calls it the Clash of Absolutes. He summarises the Pro-Life position thus: "No right is more basic than the right to live. And the untimely death of a young child is among life's most awful tragedies. 
To cause such a death is a great wrong. And if infanticide is wrong, is the destruction of a foetus at eight months of gestation, or at five, any different?". He defines the Pro-Choice position this way: "Nothing is more devastating than a life without liberty. A life in which one can be forced into parenthood is just such a life. Rape is among the most

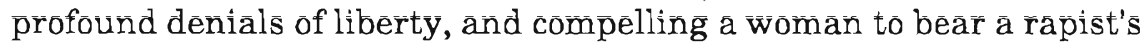
child is an assault on her humanity. How different is it to force her to remain pregnant and become a mother just because efforts at birth control accidentally failed? From her point of view, that pregnancy is also unsought." (1992:3) Life is thus pitted against Liberty in the debate over abortion.

\section{“HER BODY, HER RIGHT": THE PRO-CHOICE POSITION IN SRI LANKA}

The Pro-Choice stance adopted by the Women's NGO Forum in Sri Lanka neither acknowledges nor counters the Pro-Life argument that asserts and affirms respect for life. Instead, "Her Body, Her Right" offers a bodily integrity argument: a woman's right to her own body. Paraphrased, this argument would go something like this: the woman has sovereignty over her own body; neither the state nor any other person can violate her bodily integrity without her consent. The Sri Lankan law that criminalises abortion thus violates a woman's right to make decisions regarding her own body. It follows from this argument that while the foetus is still implanted or located within the woman's body, she may do what she likes with it. An argument for liberalising abortion laws, formulated in such a fashion, however, is problematic. Simply put, a question can be raised whether members of a society men or women - can do what they like with their own bodies. The answer might be "yes they can", but within limits. A person might change the shape of his/her nose if $s /$ he does not like its shape but $s /$ he might not cut it off at will without a licensed physician's authorisation. Organ/tissue/bone marrow donation, if done under state supervision, is legal but not organ sale. (In India, organ sale was banned by law after reports that some poor people had started selling their kidneys to wealthy patients in need.) In other words, the state regulates what its citizens could do with their own bodies. Even suicide, or attempted suicide, until 1998 was a criminal offence in Sri Lanka for the same 
reasons. The government's decision to de-criminalise suicide/attempted suicide arose from the new thinking on suicide that such people need help, not censure. ${ }^{11}$

But when it comes to abortion, this invocation of absolute rights over one's own body fails on another count. Here, there is another "potentially human" life at stake: that of the foetus. Under existing Criminal Law, taking another person's life is murder and therefore a punishable offence. It could be argued that the foetus is not yet life, only "potentially" human life. Yet, permitting a woman to do what she will with the foetus at the eighth or ninth month could, at least at a theoretical level, pave the way for infanticide at some future date. Under the present Sri Lankan law, however, abandoning a newborn at birth is criminal neglect and parents do not enjoy absolute rights over their own offspring (Goonasekere 1996:15). Such laws advance or protect the interests of women too since they guard against such practices as female infanticide and other forms of discrimination against girl children due to customary gender norms. The Compulsory Education Law, for instance, introduced in January 1998, makes parents accountable for keeping children, between the ages of 5-14, in school (Samarasinghe 2002:196). Therefore some, who oppose abortion on principle, fear the trivialisation of human life that it implies. If a woman is permitted unconditionally, at all stages of the pregnancy, to do what she likes with the foetus, then theoretically at least, there is a trivialising of human life whereas the continuation of human society, indeed its very survival as a species, is predicated upon an affirmation, not a denial, of life. As Ronald Dworkin puts it:

A state might properly fear the impact of widespread abortion on its citizens' instinctive respect for the value of human life and their instinctive horror at human destruction or suffering, which are values essential for the maintenance of a just and decently civil society. A political community in which abortion became commonplace and a matter of ethical indifference, like appendectomy, would certainly be a more callous and insensitive community, and it might be a more 
dangerous one as well ("The Great Abortion Case," 1989:50).

Certainly, no one concerned with women's issues (or even human rights) can be indifferent to such a trivialisation of human life or suffering since the tendency for long has been to trivialise or devalue the suffering women endure in various situations as part of their gendered existence in society - as socially necessary, or as part of the woman's lot in life. A good example of this is violence against women in domestic situations which patriarchal social hierarchies - family as well as state functionaries - in Sri Lanka tend to trivialise under "what is a slap from one's husband or father anyway?"

Moreover, the pithy declarative statement chosen by the Women's NGO Forum, "Her Body, Her Right," invokes a concept of absolute liberty that no society supports or in fact endorses. All societies, eastern and western, recognise the concept of individual liberty only as long as it does not infringe upon the rights of another because this notion of absolute liberty of the individual does not foster sociality. As Wai-chee Dimock reminds us, rights must be perceived as rights against somebody else. In that sense, one individual's rights modify another's. Rights defined this way presents them in relational, not absolute, terms (1990:32). A good example is the prohibition of smoking in public conveyances or places. The prohibition attempts to prevent the smoking individual from doing damage to the health of others, through the phenomenon of passive smoking, though s/he may jeopardize his/her own health in the privacy of home. The same issue is raised in the US with regard to the sale and consumption of pornography which some liberals and liberal feminists defend as an individual liberty but which many feminists refuse to locate within the rubric of individual liberty since it has both direct and indirect adverse impacts on the status and safety of women in society (MacKinnon 1987:15). Individual liberty the freedom to do what one feels like - in other words, needs to be regulated and ordered in certain circumstances by an overarching body - whether this body is imagined in terms of social consensus or the state. HLA Hart calls this "the justified limitation of one person's freedom by another" (Dimock 1990:31-32). It is this concept of ordered 
liberty that is fueling an attempt to prosecute pregnant women who "do drugs" in the US and consequently give birth to addicted newborns. Although liberals and feminists in the US have come out strongly against this unacceptable intrusion of the state into a woman's life, it is a good example of the state's interest in ordering the liberty of individuals, even in a liberal democracy such as the US. The Women's NGO Forum's declaration, "Her Body, Her Right", does not make clear when the woman's right to her own body begins to infringe upon the rights of the foetus, a potentially human life.

Indeed in an Asian or South Asian context, demanding abortion rights using a privacy argument may work against women's interests and welfare in some situations. The reinstatement of a private sphere that is beyond the interest and intervention of the state could create a space in which women's rights could be violated with impunity. In India and China, for example, abortion on demand, without state regulation, in the interest of population control, has led to sex-selective abortions. In these countries where traditional son preferences, combined with modern technology and socio-economic policies, have led to large numbers of female foeticide and infanticide, women's activists are demanding more state supervision and regulation of abortion - what is known in feminist parlance as "protective interference" (Poovey 1992:240). Although such overt son preference is not evident in Sri Lankan society, the possibility of sex-selective abortions, at a future date, cannot be ruled out in a country where patriarchal attitudes and dowry practices in all cultural communities signify a symbolic devaluation of the feminine gender, as well as unduly burden those who have girl children. Moreover, the woman's right to reproductive autonomy argument works only if women can be visualised as freely thinking and freely choosing agents who may indeed make such reproductive decisions without cultural or familial pressure. However, as the Indian and Chinese examples show, the right to terminate a pregnancy or not may not always rest with the woman alone because her spouse, in-laws or family might coerce her into making that decision. Even if she ostensibly makes the decision, it may reflect internalised patriarchal attitudes regarding female worth. Female foeticide in India and China is a good example where it is the women themselves who 
sometimes demand abortions of female foetuses. In other words, for reproductive autonomy to be effective in practice, in real life situations, women must be able to freely make the decision. In Sri Lankan society most women do not enjoy such autonomy. Thus, it is not enough to demand a liberalisation of the abortion law - the right to make decisions on reproduction - in isolation from all other cultural attitudes and practices that enforce the inferiority of women vis-à-vis men, and their dependence on the various patriarchal figures in their lives.

The basic problem with the phrase - "Her Body, Her Right" that the Pro-Choice lobby in Sri Lanka has selected to assert its support for a more liberal abortion law is that it presupposes or visualizes a rights-based culture in which the individual becomes the locus/repository of those rights. The question is whether Sri Lanka can be characterised as a rights-based society. Sri Lankan society which instills duties rather than rights in the minds of its members, and advances, community rather than individual interests as the path to social good is not fertile ground for such a discourse on individual rights. "Choice, privacy, rights" are the basic tenets of liberal individualism, which is, to some extent, alien to the Sri Lankan socio-cultural ethos. Lawrence Tribe in fact regards such notions as individual worth uniquely American. Thus, "her body, her right" can be deemed an imported rhetoric - imported from the US - which is not adapted to fit or address local needs. The notion of individual rights - in the form of natural and fundamental rights - has a long history in Western Europe that goes back to the enlightenment and records a slow evolution from the $17^{\text {th }}$ century in line with important socio-economic and political transformations. John Locke, the $18^{\text {th }}$ century philosopher, articulated best this new thinking when he said, "Every man has a property in his own person; this no body has any right to but himself" (Dimock 1990:28). Some theorists would in fact link the emergence of individualism in Western Europe to the ideology of liberalism in political terms and the ideology of capitalism in economic terms. Its entry into Sri Lankan political parlance - in the form of fundamental and inalienable human rights, the right to life, for example - is very recent. That entry in fact might have something to do with the tendency of western donor countries to link aid to the human rights record of recipients, a tendency that some call "human rights diplomacy." 
In fact, the general social ambivalence or indifference regarding individual rights is reflected in the 1978 Sri Lankan Constitution, which asserts on the one hand an individual's right to be free of discrimination on the basis of gender (among other factors) but on the other hand asserts the right of different communities to practice their religion and culture. This right to practice one's culture and religion upholds a system of personal laws - Thesawalamai, Muslim Personal Law, and the Kandyan Law as opposed to the General Law Marriage Ordinance that violates the right of women belonging to certain communities to be free of discrimination on the basis of gender - or in legal parlance, equal protection under the law. So Radhika Coomaraswamy states: "the different personal laws are a reminder that all men may be equal but all women are not - a lot depends on whether she is born to a Kandyan, Muslim or Tamil, or a 'general' family" (1991:3). Coomaraswamy's ironic reference to a "general family" highlights not only the anomalies that characterise family law in Sri Lanka but also the frustration of local feminists - Savitri Goonasekere, Kumari Jayawardena and Sunila Abeyesekera among them - who have focused attention on the clash that keeps women's rights hostage to minority politics without being able to propose a compromise that safeguards both minority and women's rights. ${ }^{12}$

A question can also be raised as to whether the move to a rightsbased culture is necessarily good and desirable. Even in the US there has been increasing criticism of the proliferation of rights from those on both the left and right of the political divide. According to Martha Minow, "some conservatives criticise the expansion of rights for contributing to adversariness and social conflict" while left-wing critics critique the rights discourse for failing "to promote community and responsibility" "Interpreting Rights" 1987: 19). JGA Pocock, for instance, speculates that the rights rhetoric might lead to an "extra-civic" and "ego-centered paradigm" that is undesirable while Emile Durkheim asserts that "one can exercise a real right only by thinking oneself alone in the world, without reference to other men" (Dimock 1990: 27). Thus the new thinking on rights, emergent in the West, criticises the discourse on rights "for presupposing and reinforcing a notion that every individual is autonomous and disconnected from others, instead of 
connected in important ways to other individuals and to society in general" ( "Justice Engendered" Minow 1987:37). In the East, proponents of "Asian Values" fault the West "for associating human rights exclusively with the civil and political rights of individuals and isolating the individual from the dynamics of life in the family and community" (Goonasekere 1996:1). Rosalind Petchesky, a feminist, strikes a timely warning: " . . the ease with which the principle of individuality and control over one's own body may be perverted into bourgeois individualism - and capitalist greed - should make us pause" (1990:8). Of course, it is possible to see this critique of the rights rhetoric as an attempt to prevent previously dispossessed social groups from claiming what is rightfully theirs - in other words, an attempt to maintain the status-quo, whether of gender, class or race. Rights activists have been quick to point out that at least in the past such non-conflictual social relations were achieved at the expense of the liberty and happiness of certain groups of people who through sheer coercion (e.g. slaves or serfs) or socialisation (e.g. women) were compelled to accept the status quo. So states Savitri Goonasekere: "The concept of duty and loyalty to communitarian values is often manipulated in such a way as to perpetuate the status quo in power relations, and deny the very humanity of the individual" (1996:3). Any critique of the rights discourse in other words must be approached with caution.

Yet, even from a purely legal point of view, the NGO Forum's declaration of a right to privacy, as in "Her Body, Her Right," appears problematic. "Her Body, Her Right" was part of a successful legal strategy that made a woman's right to choose whether to terminate a pregnancy or not a fundamental right protected by the US Constitution. In the landmark Roe $v$ Wade case decided in 1973, the Pro-Choice lawyers used a privacy argument to assert the woman's right to make decisions regarding her own body. Their argument was founded on the "liberty clause" of the $14^{\text {th }}$ Amendment to the US Constitution. ${ }^{13}$ A whole series of Supreme Court decisions prior to Roe had recognized the right of individuals to "decide for themselves ethical and personal issues arising from marriage and procreation" free from governmental intrusion (Poovey 1992:239). And this legal precedent was invoked and asserted successfully in Roe as well (Tribe 1992:80). The Sri Lankan Constitution 
however contains no such "liberty clause" that might become the basis of a successful Constitutional challenge to the restrictive law on abortion. However; the Constitution contains an equality clause that might become the basis of such a challenge: Articles 12 (1) and 12 (2) state that no person can be discriminated against on the basis of gender. Indeed, even in the US, subsequent challenges to the right guaranteed in Roe, especially the landmark 1989 Supreme Court ruling in Webster $v$ the Reproductive Services of Missouri, have made certain legal scholars and theorists argue that abortion rights should have been made a Constitutional guarantee under the equality clause, not the liberty clause, because the same $14^{\text {th }}$ Amendment guarantees equal protection of the law. ${ }^{14}$ Whether the Sri Lankan Constitution can declare the law on abortion unconstitutional, since the law in question (passed in 1883) predates the Constitution now in force, is a question for legal theorists to ponder. ${ }^{15}$ This paper makes the point that the Pro-Choice lobby needs to find an argument that might work within a Sri Lankan cultural context and within the legal framework offered by the Sri Lankan constitution.

What is more to the point is that even in the US, the right to privacy argument was not unequivocally endorsed or upheld by the Supreme Court when it came to a pregnant woman. The Court in fact explicitly declared that "a pregnant woman cannot be isolated in her privacy" (Poovey 1992:244-45). Therefore, in Roe v Wade, the Court set out to enumerate a limited right to privacy during pregnancy. According to the elaborate trimester scheme the Berger Court laid down, a woman has unrestricted access to abortion only during the first trimester of pregnancy. During the second trimester, the Court recognised the right of the state to regulate abortion but only in ways designed to preserve and protect the woman's health. But during the third trimester, the state may prohibit abortion because of foetal viability which the Court called "a potentially human life" - unless the mother's life is in danger (Olson 1989:2). The Women's NGO Forum's formulation of abortion rights is problematic because it appears to be demanding a blank check abortion on demand, during all stages of the pregnancy. They seemingly ignore thereby the rights of the foetus - a potentially human life and society's duty to protect and affirm life. They also seemingly overlook 
the fact that in the latter stages of pregnancy abortion can be as risky as childbirth and therefore there should be more supervision and regulation by the state. Ultimately, they signify no awareness of the fact that individuals cannot always do what they like with their own bodies since that concept of liberty is anyway conditional: only as long as it does not infringe upon the rights of somebody else.

\section{A RIGHT OF PRIVACY OR A RIGHT OF EQUALITY?}

The task then for those Pro-Choice advocates in Sri Lanka who wish to make the law more liberal is to formulate a more viable line of argument when it comes to abortion rights. This author is of the opinion that there is nothing inherently wrong with a rights-based approach to the issue since Sri Lanka is being compelled to move more and more towards a recognition of rights - in the form of fundamental and inalienable rights - if not towards a rights-based culture, due both to pressure from outside as well as developments within. The problem has more to do with the invocation of a privacy argument to frame the discourse on abortion in Sri Lanka which, as pointed out earlier, does not resonate positively within a (Sri Lankan) context that in a very real sense - both a socio-cultural and legal sense - does not recognise one's right to privacy. This paper argues that a right to equal treatment - or nondiscrimination on the basis of gender - is a more powerful and effective argument within the Sri Lankan context at present since a) there is an equality clause in the Sri Lankan constitution that at least offers a theoretical guarantee of non-discrimination on the basis of gender; $b$ ) in many ways, the inherent inequality between the genders underlies, and manifests itself in different guises in the opposition to abortion.

An argument could be made that equality is no more central to Sri Lankan culture than privacy. However, the Sri Lankan constitution recognises equality as a basis for citizenship at least in principle and it is lack of equality, not denial of privacy, which manifests itself in the continued opposition to a more liberal law on abortion rights. Moreover, as Martha Minow suggests, it is possible to "include within the ambit of the rights discourse all efforts to claim new rights, to resist and alter state action that fails to acknowledge such rights, and to construct 
communities apart from the state to nurture new conceptions of rights"("Interpreting rights" 1987:19). However, as she also points out, since a rhetoric is intended to persuade, it must resort to an emotional and intellectual register that makes sense within the local context for, "[r]ights represent articulations - public or private, formal or informal - of claims that people use to persuade others (and themselves) about how they should be treated and about what they should be granted" ("Interpreting rights" 1987:19). Therefore, rather than claiming the right to abortion on a privacy argument - that is, on the basis of a "handsoff" policy by state and society - Pro-Choice advocates would do well to explore the possibility of framing the demand for a more liberal law on abortion on grounds of equality between the genders. In order to do that, they would need to highlight those particular dimensions to women's reproductive selves and sexual identities that are involved in the debate over abortion and how opposition thus signifies an unwillingness to rectify those inequities that characterize women's lives in Sri Lankan society.

To demand a liberalisation of the abortion law on an equality principle, i.e., on the basis of equal treatment for both genders, is to present abortion as a women's issue. The question that then needs to be addressed is how abortion is a women's issue and how gender inequality subtends the opposition to abortion. For most Pro-Choice advocates, it is a given that abortion is a women's issue. Clearly, from a medical or health perspective, it is a women's issue since it is women's reproductive health that is jeopardized in back-alley abortions performed by incompetent personnel with little attention to safety standards. Legalising and liberalising abortion law, with state-regulated safety standards and/or state-provided services in place, would therefore protect women's reproductive health and even save women's lives.

Yet, Pro-Life advocates frame the issue of abortion rights differently. For them, it is a moral and philosophical issue that has to do with respect for, and affirmation of, life - in this case, affirmation of the right to life of the foetus. Since the foetus cannot protect itself, it must be protected, goes the argument. At a theoretical level, this "vulnerability" argument is not one that anyone can quarrel with since 
our notions of "humanity' within a modern socio-political context requires that we extend adequate protection to the vulnerable against the more powerful in society. Indeed, that is one argument in favour of rights rhetoric: guaranteeing a "system of individual rights" against "majority tyranny" (Dworkin, "The Future of Abortion," 1989:31).

But there is an inherent flaw in this Pro-Life argument. Those who defend the right to life of the foetus assume women to be among the powerful in society and thus ignore the gendered vulnerability of women in patriarchal societies. Two situations in which abortion is not legally permitted in Sri Lanka would underscore the point just made very clearly: rape and incest. Rape and incest are among the best examples of feminine vulnerability and powerlessness. The high incidence of rape in Sri Lankan society (reported to be on the rise) demonstrates the presence of male dominance and female powerlessness in a very real sense, while incest shows the systemic oppression and subordination of the feminine gender, since even within the privacy of home and family, they may not be safe. Those who wish to protect the foetus from harm assume women have the right to say "no," that women in that sense are autonomous agents when it comes to sexual decision-making. Yet, it is a fact that there is a high incidence of coerced sex or absence of consent in sexual encounters in many heterosexual encounters, including marriage. That is why, in 1995, the then Minister of Justice attempted (though unsuccessfully) to include a category called marital rape when amending the law on rape (Abeyesekera 1997:87). Moreover, a married woman might become involuntarily pregnant as a result of a non-consensual sex act with her husband in an alcohol-induced stupor. An unmarried woman might end up pregnant in an attempt to keep a boyfriend from straying, in her desperate desire to secure a marriage partner in a cultural context that requires all adult women to marry. In both hypothetical scenarios, the woman's ability to exercise free choice in whether or not to become pregnant is very limited, and in both, a combination of contingency and ignorance may prevent the woman from protecting herself against an unwanted pregnancy. After all, while information on and accessibility to contraceptives is available, culture-induced inhibitions may prevent many women from locating and approaching those institutions where 
such support is to be found such as hospitals and clinics, public and private. Indeed, a critical finding of a survey carried out among health care service providers on their attitudes to liberalizing abortion law and services revealed that a large majority did not "approve of contraception for unmarried women" (Hewage 1994:333). Moreover, it is not known to what extent women exercise free choice when it comes to family size, sexual relations and contraceptive use even within marriage in a patriarchal society such as Sri Lanka, which enforces female subordination and submission to the patriarchal figures in their lives, especially husbands. There is evidence that a major reason for unplanned and unwanted pregnancies is the failure or unwillingness of husbands and male partners to cooperate on contraceptive use and to agree to birth spacing and limitations on family size. In such situations, abortion, which can be undertaken without the husband's knowledge, consent and interference, becomes the woman's sole refuge in order to avoid an unwanted pregnancy (Hewage 1994:331). Thus, abortion, however undesirable, becomes the only available recourse to a woman who desires to exercise some control over her reproductive self. Indeed, available research indicates that a substantial percentage of those seeking abortions are married women whose reasons for seeking abortion services range from economic hardship to birth delaying, birth spacing and completed family (Sirisena 1991:4-5; Hewage 1994:326). In other words, the vulnerability of the foetus cannot be asserted against a pregnant woman assumed to be free and powerful. Pro-Choice advocates would need to highlight the vulnerability of women's status in a patriarchal society such as Sri Lanka and pose the question whether the right to life of the foetus can be asserted at the expense of the right to life of the pregnant woman in such circumstances.

Most Pro-Life advocates fail to realize that pregnancy perceived in the abstract is not the same thing as actual pregnancies visualised in context. An unwanted pregnancy could leave a real woman's life in shambles - a real woman with a very real life, very real hopes, and very real pain. And there is both a social and economic cost to pregnancy if imagined within the particular context of Sri Lanka. To begin with the social cost, Sri Lankan society frowns upon pregnancy out of wedlock. A woman pregnant out of wedlock will therefore face both 
familial and social censure from the family, in certain instances, who might pressurise the woman to abort in order to save face. Thus, in Sri Lanka, the social cost of pregnancy out of wedlock is not to the woman alone but to her family as well. Indeed, the social cost extends to the innocent child as well who must forever remain the bearer of the "original sin". Until very recently, the Sri Lankan birth certificate, for instance, recorded the "legitimacy" of the birth. Though the official requirement is now done away with, social attitudes towards legitimacy, to be derived from the father, still persist. Does such a society then have the moral right to demand that women mother at all costs? The patriarchal nature of society manifests itself in this contradictory attitude that demands on the one hand that all pregnant women mother but selectively endorses, or bestows approval on, certain pregnancies against others. As Jayantha Sirisena points out, "we oppose the destruction of these individuals while they are in their mothers' womb, but continue to destroy them and their mothers in a much more devastating manner following their birth" (1991:4). It would then be correct to assert that both the legal ban on, and religious opposition to, abortion are fueled by patriarchal authority figures - men and women - who have never had to face the issue of an unwanted pregnancy.

The requirement that all pregnant women become mothers appears even more unjust and unreasonable in cases of rape and incest. A theoretical assertion of the foetus' right to life would require that the woman victim of rape or young girl impregnated by her own father or close relative carry such pregnancies to term. To the question of whether such women be compelled to mother, Pro-Life advocates would respond with the image of the guiltless life within. While the foetus is indubitably innocent, attention can be drawn to the status of the innocent woman victim who must live with this living proof of the violation of her bodily integrity. ${ }^{16}$ The point here is that pregnancy should not be imagined as undertaken by freely-choosing and acting agents at all times. There are different degrees of absence of will and choice in pregnancy. Rape and incest are also reportedly on the rise in Sri Lanka due both to the civil war and migration to the Middle East in search of employment by married women who must leave behind older female children with their fathers or other family members. ${ }^{1.7}$ In such 
circumstances, the requirement that all pregnant women mother (except those whose lives are at risk in a medical sense) demonstrates the relative indifference to, and even ignorance about, the women's status and options within the existing gendered status-quo. After all, there are more reasons than one that make a pregnancy unwanted, and in some instances society is itself culpable in the designation of a pregnancy as "unwanted."

There is also an economic cost to pregnancy. Again a theoretical assertion of the foetus' right to life ignores the fact that a foetus once born, must be fed, clothed, sheltered and educated. And there are many pregnant women who cannot afford to perform these necessary functions of mothering. Those who think children are priceless may not wish to calculate the economic costs of child-bearing and rearing. Yet it is costly to bring up children and in today's money-driven world the costs continue to rise. A poor married woman with several children who becomes pregnant as a result of a faulty birth-control device or drunken husband must decide between the life of an unborn against her already living children. In Sri Lanka, as elsewhere, failure of contraceptive methods constitute a major reason for pregnancy termination (Sirisena 1991:45; Crane 1994:258). In addition financial hardships join failed birthcontrol devices as another reason for induced abortion in Sri Lanka (Sirisena 1991:4-5; Hewage 1994:326). It is an unenviable choice. For the many married women who enter the low-wage, low-skilled pool of private sector jobs through economic necessity marriage, let alone pregnancy, can constitute grounds for job loss. ${ }^{18}$ Even state sector employees, the most privileged in terms of employment benefits, may enjoy the full 84 . working days of maternity leave for only the first two live births. There is a drastic reduction in the leave granted (only 42 days) thereafter. Indeed, in Sri Lanka, many employers in the Export Processing Zones who recruit women do not consider pregnancy and motherhood a legitimate and valued part of the lives of their employees. ${ }^{19}$ These jobs also do not offer any maternity benefits such as paid leave, nursing intervals, or day-care centres. Nor does the state try to encourage or compel these private sector employers to grant such rights, which are available to all state-sector employees because of fears that the foreign investors might pull out. (The state has a justified 
fear of the social unrest that results from widespread unemployment.) Thus, given current political and economic realities, some women cannot afford to mother: On the other hand, those opposed to abortions undertaken for economic reasons are generally from the social and economic elite who have never had to calculate the economic costs of parenting. In other words, there is a class, as well as a gender dimension to the abortion rights debate since it is those from low-income backgrounds who must calculate the economic costs of pregnancy and it is they who are most at risk from unsafe abortions performed in back-alley abortion clinics. Those who have the money can, after all, get an abortion performed in the relative safety of private nursing homes by qualified medical personnel. But the Rs 10,000-12,000 charged is beyond the means of many Sri Lankan women.

The position of Pro-Choice advocates' would be stronger if they assert the right of women to mother as well as not to mother. The reason Sri Lankan society demands women to mother without making it possible for women to mother in either social or economic terms has after all to do with a simultaneous naturalisation and devaluation of pregnancy and motherhood. It is a fact that women bear and remain the primary rearers of children due to an accident of biology. However, as many feminists have pointed out, motherhood, as it is understood today, is a social construct whose social dimension is concealed so that it may appear natural - the way things are. In Sri Lanka, there is very definitely a naturalisation as well as a glorification of motherhood that lures women into voluntarily assuming the role. But it is also the case that in Sri Lankan society motherhood is conceived in terms of its duties, not in terms of its rights. In popular cultural icons such as songs and folklore, motherhood is therefore synonymous with sacrifice. Thus Sri Lankan society, like many other societies, has avoided the need to revalue mothering and parenting - a need that would only arise from the recognition that motherhood is a social as well as a personal/private need. In other words, if women choose not to mother the very survival of society would be at risk. It is in fact ironic that in Sri Lanka where heightened inter-ethnic rivalries have created an interest in numbers and exhortations to. women to do their bit for the cause of ethnicity, there is still no move to facilitate "mothering" through material means! 
Instead, located in the seemingly private sphere, mothering is cast in terms that supposedly bring symbolic, not material, benefits. It is therefore necessary, that Pro-Choice advocates engage in a revaluation of the work women do as mothers and housewives - in producing and maintaining both potential and active participants of the labour force (as well as adding to the numbers!). The devaluation by the Sri Lankan state and society of the role of women in reproduction is confirmed in the patriarchal practice that legally invests the custody of children with fathers, in both symbolic (the name) and real terms (in case of divorce and when it comes to citizenship rights). And it does not, in tangible terms, support the right of women to mother by providing quality prenatal and post-natal care, substantive maternity leave and benefits, food assistance, cash grants, day care services, affordable housing, tax benefits, etc. Since Sri Lankan society does not provide many of these supports for pregnant women in need of such assistance, a question can be raised whether it can demand from women that they mother at all costs. Right now, malnutrition is rather high among pregnant women as a result of which there is also a high incidence of low birth-weight babies (Samarasinghe 2002:159). In many Western European societies, where the right to not mother is recognised through more liberal abortion laws, there is also assistance provided to pregnant women who wish to be mothers. But in Sri Lankan society, the unacknowledged norm is still the married housewife - the woman who stays home and can sustain any number of pregnancies without too much difficulty. However, as pointed out before, due to both socio-political and economic transformations, the real picture is very different. This normative image of Mother as married housewife today must be modified by other images such as working mother, single mother, unwed mother and teenage mother. These "other" types of mothers are increasing in number due to civil disturbances in the North and East, female migration to the Middle East; changing sexual norms and practices influenced by the media, increase in low-paying private sector jobs for women, etc. For example, female-headed households are on the increase in certain parts of the country due to civil disturbances in the North, East, and South. ${ }^{20}$

This social construction of motherhood partly inflects the attempt to present the foetus and the pregnant woman in adversarial 
terms, and to present the foetus as a bearer of rights. But as some legal theorists have asked, is the foetus a person, since it is only a person that in legal terms can enjoy rights (Dworkin, "The Great Abortion Case," 1989:50-51). Can an unborn, in other words, have rights? Those who may be willing to concede that the foetus is not a person in the legal sense may still argue for the foetus' status as a living being and therefore entitled to such protection. As Dworkin points out, although the foetus may not be a person in a legal sense, it is "an entity of considerable moral and social significance to our culture" "The Great Abortion Case," 1989:52). But if the foetus is valued as a life form, this begs the question when life begins. Is it at birth, at some point in the gestational cycle, at implantation in the uterine wall, or at the point of fertilisation? This is a question that science has not been able to answer decisively (Tribe 1992:116). It then becomes, as some point out, a moral and social question. If the value accorded to life, in fact the very origins of life, is a social and moral question, the insistence that life begins at fertilisation, which makes abortion illegal at any stage, results in a devaluation of the life and contribution of the woman who does the work of transforming a dot-like embryo to a fully-formed foetus and then baby. Pregnancy, after all, is a process that moves from fertilisation to gestation to delivery-stages during which the pregnant woman plays an active role. It is her commitment in terms of her health, life-style and attitude that makes a healthy newborn possible, although "advances in neo-natal technology," according to Rosalind Petchesky, are turning the foetus "into a patient, if not a person"(1990:xiv). Moreover, pregnancy is no temporary inconvenience but a long-term commitment that goes beyond the initial nine-months of gestation. In terms of health too, the costs can be permanent. Those who pit the foetus against the pregnant woman also ignore the fact that in a very real, physiological sense, the foetus is dependent on its mother for everything, and that until foetal viability occurs somewhere at the beginning of the third trimester, it cannot survive apart from its mother. Indeed, before advances in medical knowledge and technology made early detection of pregnancy possible, and before the emergence of a transnational discourse on and a coalition opposed to abortion, "quickening," or foetal movement, was the cut-off point between permissible abortion (simply known as "becoming regular") and its 
opposite (Petchesky 1990:69). In other words, biological embodiment is not in itself grounds for a separation of the interests of the foetus from its mother. The foetus needs the pregnant woman to bring it to term since artificial or mechanical wombs are still not on the horizon (Tribe 1992:220). Its assertion of life, then, cannot be at the expense of the right to life of the mother.

Moreover, Pro-Life advocates who see themselves as the guardians of the "innocent" foetus against its mother operate under the assumption that women are not capable of making such difficult moral decisions for themselves. This assumption arises from certain traditional pairings that associate women with children, a pairing that denies women their status as autonomous moral agents. They trivialise thereby the ambivalence, the guilt, and the very real pain of the woman who must make the difficult decision to abort. There are of course those who suggest adoption as a solution for unwanted babies. But they forget the commitment of the pregnant woman to make the foetus viable and the resulting bond between pregnant woman and foetus that might make it hard for a woman to give a newborn up for adoption. (Those who fail to see pregnancy as a process do not realize that the woman's bond with the foetus is an evolving one that makes it easier for her to accept a miscarriage in the early months than a spontaneous abortion in late pregnancy or a still birth.) In the Sri Lankan context, they also forget that adoption is not widely practiced and such unwanted children generally end up in sub-standard children's homes. However, as Rosalind Petchesky correctly points out, Pro-Choice groups, especially feminist groups, too have been lax because they have not "articulated a feminist morality of abortion" that gives adequate recognition to the weighty issues at stake: "Life" v "Liberty." Such a feminist morality is needed to counter the emotionalism and moral outrage of the Pro-Life groups (so far mostly in the US) and their impact on those they try to woo via images of the hapless foetus, and the intense guilt of the women who have to make the difficult decision to go through an abortion. ${ }^{22}$

Finally, behind the opposition to abortion is a sexual double standard that expects from women a higher standard of sexual morality and reproductive responsibility. As Radhika Coomaraswamy explains, 
in a slightly different context, Lankan culture regards its women as the guardians of its morality and repository of its cultural values ("The Impact of Tradition, Culture and Religion," 1988:70). For this reason, the sexual transgressions of men and women do not receive the same level of concessions or condemnation. After all, it is a simple lesson of biology that pregnancy is not the work of a woman alone. Sri Lankan society however does not hold the man responsible or culpable in a social and moral sense for any pregnancy outside of approved norms. (Legally, though, a man may be held financially accountable to support a child born out of wedlock if proof can be supplied of his paternity.) Behind the opposition to abortion then might be a punitive element a desire to punish those women guilty of sexual transgression although; as mentioned earlier, in Sri Lanka, a substantial percentage of those seeking abortion services are not single women pregnant out of wedlock. Frances Olson suggests a punitive dimension to the anti-abortion laws for they seek to separate and punish "bad" girls:

Anti-abortion laws treat women as blameworthy for becoming pregnant and penalize them for their sexual transgressions: they presuppose and punish the badness of bad girls. Good girls never need abortions and bad girls do not deserve safe, legal abortions. The double standard denies sexual freedom to "good girls" while it legitimates the sexual exploitation of "bad girls" (1989:28).

The double standard may also arise from an assumption that women are without sexual drive and desires and that sex is for procreative purposes only. However, opposition to abortion restricts this sex-for-procreation requirement to women only and in that sense might be seen as a gendered control on women's sexual expression and reproductive freedom. For, anti-abortion laws combined with the difficulty of access to contraceptives, in a very real sense, make's biology their destiny for many women and unfairly handicap them in relation to men when it comes to autonomy and mobility in an economic sense as well as when it comes to sexual expression and sexual relations. Thus, a restrictive abortion law keeps women dependent on men in 
economic and sexual matters and in that sense poses a very real barrier to equality (guaranteed by the Constitution) between the genders in our society.

\section{EQUALITY OR EQUTTY?}

This critique of the discourse on Abortion Rights in Sri Lanka cannot end, however, with the suggestion that the equality principle is the perfect alternative to the problems posed by the privacy argument. As feminist theorists have pointed out, there are problems with the equality argument as well when it comes to gender, and these stand revealed very clearly in fact in this very debate over abortion rights for women. Equality presupposes an equality with somebody, or a relative inequality in terms of status and rights of one group vis-à-vis some other. When it comes to gender inequality, it means the relative inequality of women in relation to men. There are dangers as well as problems inherent, however, in an argument for women's rights framed in terms of an equality principle: that is, women are the same as men and therefore should be granted what men have. First of all, it reifies, as Martha Minow points out, the (heterosexual) male as the norm, the standard against which women's rights, or what women have, should be measured and found wanting (1987:12). This means women can have only what men have. It also means women cannot have what men do not have, do not want, and do not need. Catherine MacKinnon calls this the "sameness" argument (1987:33): women are the same as men; it is only patriarchal attitudes and practices that presume and instill a difference and inequality based on that difference between men and women.

However, in recent years, feminist theorists have begun to express dissatisfaction with the argument for women's rights framed on the basis of the sameness principle. They have begun to ask: are women the same as men? Do we always want to be like men? Do we want only those rights that men enjoy?"2 Although the term "gender" highlights the social interpretations of sexual difference, this gender difference is built upon a basic biological difference between male and female. And this biological difference necessitates that in some instances 
women be seen as different from men and be accorded certain rights that men do not enjoy or need. The best example of this is the rights attendant upon the unique reproductive role of women. This role requires that women be accorded certain rights that men do not have, and do not need. It means social and economic assistance to women who wish to be mothers, and legalised abortion for those women, who for whatever reason, do not wish to carry a pregnancy to term. Drucilla Cornell suggests the term "equivalent rights" to categorize those rights that women require as women but are not accorded under the existing patriarchal systems that take men as the norm: "Very simply, rights should not be based on what men, as conventionally defined under the gender hierarchy, need for their well-being, as if there was only genre of the human species" (1992:293). Only a concept of equity, not equality, would guarantee women such rights.

Thus "difference" again re-enters the picture but in a different guise. "Different" now does not mean inferior: "These rights are equivalent because they allow difference to be recognized and equally valued without women having to show that they are like men for legal purposes or having to make sacrifices because of the specificity of our 'sex' which makes us 'unlike' men" (Cornell 1992:293). Embedded in the sameness-difference debate is what might be called the feminist dilemma: How to assert those rights that women need as women without letting "difference means unequal" make a surreptitious comeback. Catherine MacKinnon articulates this fear when she says: "The difference approach misses the fact that hierarchy of power produces real as well as fantasised differences, differences that are also inequalities (1987:37). To avoid this trap, in the case of pregnancy, for instance, there will have to be a revaluation of pregnancy and motherhood (even parenthood) as a valued social need, not merely the private need of the woman or couple concerned. In the case of abortion, the right to make the decision whether to continue with the pregnancy or not will enable women to control their reproductive capacity and thus prevent the biological difference between men and women from becoming a handicap for women socially and economically - in this instance, forcing them to go through a pregnancy that they do not want for whatever reason. This same question-how to reinstate difference 
without letting it become a disadvantage to women - faces certain American feminists too who favour affirmative action programs in favour of women. Some liberal feminists who assert the equality of men and women but who also favour affirmative action policies in place to rectify past injustices against women worry over the possibility that this reinstatement of difference might become a means once again of discrimination against women. There are other feminists who object to equality because equality homogenizes women as a group and, in that sense, erases those class, racial and ethnic differences that lead to inequality among women and result in different experiences of gender oppression. Equivalent rights to some extent addresses this problem by reinstating difference and thereby recognizing that women may require different rights depending on their other socio-economic affiliations. For example, for abortion rights to be meaningful for poor women in Sri Lanka, abortion should be made available free, or at concessionary rates, at state hospitals. The same goes for contraceptives. For affluent Sri Lankan women, on the other hand, who can pay for these services, just the legalization of abortion and contraceptive use is sufficient.

The task then before Pro-Choice advocates is to formulate a rhetoric or discourse that will make sense within the Sri Lankan context - a society that, already, at the official (legislative) level has refused to endorse a more liberal abortion law on religio-cultural grounds. According to Susanna Rance, discourse is an important means of contesting a given or dominant version of reality: "diverse social groups - including feminists - seek power and influence through contesting the discourses of others, creating and recreating their own and disseminating representations of the world in accordance with their particular and varied interests" (1997:11). However, the rhetoric or discourse deployed would have to be multi-layered considering the different constituencies or interest groups that need to be addressed such as the state legislature, religious hierarchies, health care workers, and society in general. In other words, the appeal must be formulated in such a way to resonate positively with the different intellectual and emotional registers of the constituencies who will have a say in determining the status of abortion rights in the country. 
With the state legislature, a utilitarian view of abortion is one strategy that might work: that the high number of back-alley abortions threatens the reproductive wellbeing of large numbers of women in this country. In order to make this point, the support of concerned health care professionals and activists would have to be solicited. For instance, Dr Jayantha Sirisena, an eminent Obstetrician/Gynaecologist, in a perceptive article on abortion, has pointed out the costs to society of back-alley abortions. Medical complications arising from illicit abortions, on the one hand, have a "paralytic effect on human resourcefulness" and, on the other, "absorb a large share of the medical resources devoted to obstetrics and gynaecology" (1991:3). According to him, the morbidity and mortality rates arising from criminal abortions are wholly preventable if performed under safe conditions and by trained medical personnel. Though no one can give accurate details or numbers of women dead or debilitated on account of induced abortion because of the very secrecy that surrounds the practice, a pragmatic approach that highlights the lives lost and expenditure incurred might work with parliamentarians who are only too aware of (foreign-donor exerted) pressure to reduce "welfare" spending. The point should be made that the cost is not to the individual woman or family alone but to the society as a whole since health problems resulting from back-alley abortions burden even more an already over-burdened health care system and jeopardize the state's interest in ensuring a healthy working population. Indeed, with an employment scenario that increasingly offers more job. opportunities to women - locally and abroad - their reproductive health becomes a cause for national /official concern.

Clearly, the reluctance of the legislature to reform the law arises from fears of social and religio-cultural opposition to abortion. Therefore, the community needs to be lobbied to create informed and articulate communities who will adopt a Pro-Choice stance. In the author's experience, many Sri Lankans do not oppose abortion when they are presented with the facts relating to the practice of abortion in the country. Since the social cost of an unwanted pregnancy is not to the pregnant woman alone, many Sri Lankans, if the issue is personalized (the "what would you do if your own unmarried daughter or sister got 
pregnant..." question), tend to recognize the need for a more liberal law on abortion. Certainly, informal opinion surveys suggest that many Sri Lankans would not object to abortion legalized in cases of rape and incest. However, such a narrow liberalization of the law creates more problems than it solves. For instance, how does one distinguish those pregnancies that are the result of rape and incest? In order to qualify for a legal abortion, does the woman have to report to police the rape or incest at the time of its occurrence? But in Sri Lanka most rape and, especially, incest victims and their families would prefer to keep such incidents secret with the hope that conception would not occur. So what of the woman viction of rape/incest who discovers subsequently that she is pregnant and desires a legal abortion? Moreover, how will the state distinguish the bona-fide rape/incest victim from the one who claims rape to obtain access to legal abortion? Will such a law compel the woman concerned and/or her family to "cry rape" and accuse the male partner in a consensual sex act in order to qualify for legal abortion? Moreover, will a complaint at a police station be enough or will the victim have to wait until preliminary evidence at least is compiled to substantiate the charge of rape/incest? Such arguments could be used to persuade those sections of the community that might only make allowances for rape and incest.

However, the most formidable and intransigent opposition to legalized abortion comes everywhere from the official and organized religious bodies, with the Vatican leading and/or backing anti-abortion and Pro-Life groups in many countries where there are significant Catholic communities. ${ }^{23}$ As the International Conference on Population and Development (Cairo, 1994) demonstrated, the Catholic and Islamic opposition to abortion can even result in an "unholy" alliance among two religious communities who historically have shown little interest in collaboration and joint action. ${ }^{24}$ A similar situation appears to prevail in Sri Lanka. In the impassioned debate in Parliament (1995) on the (already withdrawn) amendments to the law on abortion, the opposition to the proposed amendments came mostly from those belonging to the Christian and Islamic communities. Members of Parliament, John Amaratunga, Tyronne Fernando and Azwer, for instance, were the most vehement in their opposition to the amendments proposed (Abeyesekera 
1997:88). It could be read as a positive sign that the Buddhist and Hindu Members of Parliament - jointly comprising the majority of the Sri Lankan populace - did not adopt such a dogmatic position on the issue although it is not clear what their position would have been if the amendments originally proposed had not been dropped from the bill presented to parliament.

The question then is how to win over or neutralize opposition to a more liberal law on abortion that rests on such religio-cultural orthodoxies. Certainly, officially and collectively, an organized body like the Catholic Church (with its well-known anti-abortion rhetoric internationally) might not come out in favor of a more liberal law. But there is a possibility that at an unofficial and private level, it might work with many members of the Catholic clergy if the argument is made as an appeal to compassion and forgiveness for the "erring" woman - compassion and mercy being fundamental tenets of New Testament Christian theology. It might at least make them not mount a vociferous campaign against abortion rights. Indeed, it is a positive sign that so far there are no Church-supported anti-abortion groups in Sri Lanka. Such a subdued stance was adopted by the local Catholic Church during the state campaign to popularize contraceptive use though the Catholic Church, especially under the more conservative Pope John Paul II, also opposes artificial means of birth prevention, even for married couples (Crane 1994:248). This phenomenon supports Finkle's and McIntosh's view that there is more room for "diversity of opinion within the Church [since] the Second Vatican Council . . which ushered in an era of greater decentralization" (1994:21). An appeal to compassion, combined with the facts relating to abortion in Sri Lanka, should work with the religious hierarchies of most communities - at least, to persuade them not to actively lobby the legislature against a liberalization of the abortion laws - even if they cannot publicly endorse the practice of abortion. After all, the public posturing of official bodies is not always the best indicator of the private convictions of individual members. For example, the Family Planning Association of Sri Lanka has been in recent times publicly advertising what they call the 72hour pill (Prostinor II) which is similar in function to an abortifacient although the FPA has been quick to include a disclaimer that it is not 
an abortion pill (like RU 486). Moreover, it is a fact that Marie Stopes International is active in the country. ${ }^{25}$ Indeed, the relative "impunity" with which the FPA of Sri Lanka and Marie Stopes International-assisted clinics have been operating in the country does raise the question whether it is wise to initiate a debate and thus focus public attention on facts relating to abortion in Sri Lanka. As Barbara Crane puts it, "should attention go towards changing existing laws and policy, that is, influencing administrative decisions, or providing services within boundaries of existing policy"? According to Crane, "focusing on service allows agencies to avoid direct confrontation with policy makers and organized opposition" (1994:250). Yet, the fact remains that the abortion law in Sri Lanka is extremely restrictive while the FPA's Prostinor II works only if taken within the first 72-hours after copulation. Similarly, clinics assisted by Marie Stopes International, and therefore able to provide relatively "safe" abortion services, are few and far between. ${ }^{26}$ Moreover, the re-imposition by George W Bush, as soon as he took office in January 2001, of what is known now as the "global gag rule" that is, stopping USAID funding for those family planning and population control agencies and organizations abroad (the International Planned Parenthood Federation and the UN Fund for Population Activities among them) that use their private funds to offer abortion counseling and services - is creating a situation where US "might," that is, the moral dictates of a right-wing, Pro-Life American regime, begins to be ranged against Pro-Choice groups internationally. ${ }^{27}$ Such a situation requires that Pro-Choice groups, especially in developing countries, form transnational alliances and also influence domestic opinion and policies in favour of abortion so that they need not depend on foreign funds and may avert any American attempt, under right-wing leadership, to determine domestic policy agendas. ${ }^{28}$

Ulitimately, an amendment to the law does not necessarily and automatically lead to a change in social attitudes towards abortion. As the Indian situation demonstrates, the law alone cannot make the procedure safe for women service-seekers. Attitudes of health care workers and professionals who occupy a front-line position in the attempts to provide legalised access to abortion in state hospitals and the attitudes of service seekers all have an impact on efforts to legitimise 
abortion. In India, one study reports that both the hostility and contempt of service providers and the internalized sense of shame of some service seekers have led to the continued existence of clandestine service providers (Gupte, Bandewar and Pisal 1997:78). In Sri Lanka, too, the prevailing social climate deems the practice "shameful" and invites contempt upon both the practitioner and service seeker. ${ }^{29}$ This raises questions about the degree of receptivity among health care workers and professionals to the practice of abortion since it is they who must deliver the service if abortion is to be legalized and made available in state sector hospitals - essential if abortion rights are to be meaningful to the large numbers of low-income women who may not be able to afford fee-levying service providers. ${ }^{30}$ The Pro-Choice lobby therefore would need to devise a multi-pronged campaign that would also target employees of the health sector in an attempt to change attitudes and to make them more receptive to the idea of abortion, performed in their workplaces, and by them. One study, conducted among health-care providers in Colombo district hospitals, concludes that approximately $50 \%$ of the number interviewed were opposed to liberalizing the law on abortion although they showed concern about "unsafe" abortions (Hewage 1994:330). Moreover, it has been found that doctors the world over look down upon both practitioners and the practice of abortion, seeing it as low down in the scale when it comes to the practice of medicine and chosen only by those who have the profit motive in mind (Crane 1994:256). Such attitudes may prevent many doctors from being willing to perform abortions. Hence, a strategy would have to be devised, in consultation with concerned health care activists and professionals, to overcome such revulsion.

Moreover, concerted effort should be made to activate empathy for the women who must resort to abortion since the law on abortion can be liberalized only if all parties to the debate can develop empathy for the woman who must make the difficult decision to abort a foetus. Empathy means the ability to put ourselves in the position of another whose experiences and point of view are dissimilar to ours. In the debate over abortion, it means the ability to understand or empathize with the woman who through force of circumstances finds herself unable to bring a pregnancy to term. It would indeed be strategic on the part of the 
local Pro-Choice lobby therefore to present abortion not so much as a right claimed by a woman confident in her right to choose but as required by women who see themselves as without choice when they find themselves pregnant under certain circumstances. Abortion in fact is not a choice for most women who find themselves at the abortion clinic, that is, chosen by a woman who can freely decide whether to carry a pregnancy to term or not. Rather, it is opted for by women who see themselves as being in a "no choice" situation! Abortion in Sri Lanka therefore is not so much a manifestation of women's power but of women's powerlessness. The lobbying for the liberalization of the abortion law must be located within this bleak reality rather than in some abstract realm of rights. Such a presentation would invite empathy for the service seeker. And it is empathy that is largely lacking on the part of those who are opposed to abortion on principle. That is why, more men than women, in the author's experience, are opposed to abortion rights since men find it more difficult to visualize themselves in the position of a woman pregnant against her will. Women, on the other hand, are better able to envision a situation in which they too might have been, or might be, in need of an abortion.

However, this empathy for the woman needs to be balanced with compassion and respect for the life of the foetus - a potentially human life. This means that abortion should not be made available until the point of birth as the formulation of the Women's NGO Forum - "her body, her right" - seems to assert. Pro-Choice advocates in Sri Lanka, in other words, should not give the impression that they are demanding a blank check when it comes to the right to abortion. Instead, a reasonable time-limit should be proposed within which abortion can be made available legally, as long as the procedure is performed by a licensed physician in state-approved institutions; this is indeed the case in many countries where abortion is legally available. Fourteen to Eighteen weeks of gestation has been proposed as a humane limit to legal abortions that combines both respect for the potential human life that is the foetus and concern for the health of the woman undergoing abortions. After all, one medical argument in support of abortion is that in the early months abortion is safer than childbirth for the pregnant woman, whereas as the pregnancy progresses, abortion 
becomes increasingly more risky. Therefore, although foetal viability itself does not occur until the beginning of the third trimester, both collective respect for human life as well as concern for the health of the pregnant woman requires that concerned individuals and groups agree on this early cut-off point. This is what could be called a humane compromise between the conflicting interests and claims that fuel the debate over abortion rights in Sri Lanka and elsewhere. The right to terminate a pregnancy, it is argued, should not be absolute but conditional - but the conditions should be laid down by a society that looks at the issues at stake from a human and humane perspective, that is, with empathy and compassion, towards both the pregnant woman and the "potentially" human life within her. It may be "her body" but her right (for autonomy) cannot totally exclude the right (to life) of the foetus.

\section{Notes}

1 The number of illegal abortions in the US, for example, before abortion was legalised in 1973 by a Supreme Court ruling (in Roe $v$ Wade) was 100,000 a month (Tribe 1992:41). For Sri Lanka, the Ministry of Health, Highways and Social Services has given a figure of 750 per day for 1995 (Samarasinghe 2002:157) although the figure quoted may not be exact given the clandestine status of the practice. Thus, the number for Sri Lanka works out to between 15,000 to 21,000 a month-a rather high figure if we consider the fact that the population size of the US is approximately 25 times that of Sri Lanka.

2 Hewage quotes a study conducted at a gynaecological unit in a government hospital according to which "out of 1638 admissions over a period of six months, approximately $25-30$ per cent were cases of abortion complications" (1994:322). Jayantha Sirisena, an eminent Gynaecologist/Obstetrician, stated in 1991 that "one of the main causes of maternal deaths in Sri Lanka is abortion" (1991:1). 
3 For an extended discussion on the failure, by the Ministry of Justice to amend the Penal Code relating to abortion, see Sunila Abeyesekera, (1997:87).

The Women's NGO Forum's advertisement in 1999, aired over television and newspapers, contained the following message: "Between 500-700 abortions are conducted daily in Sri Lanka. These illegal abortions pose a serious threat to women's reproductive health. Her body, her right."

In May/June 2001, the Women's NGO Forum once again drew attention to the issue in a 2-hour TV programme, which is under their sponsorship and supervision, aired on Swarnavahini titled Kadapatha.

According to Soma de Silva (2001:52), not all deaths that arise from septic abortions may be recorded as such because the identification of the cause of death - whether maternal death or not, whether due to abortion or not - depends on the death declaration form. If the cause of death is recorded as "septicaemia following abortion," then, the death is recorded as a maternal death and its real cause can be identified. But if the cause of death is recorded as septicaemia alone, then, the death would be classified as a non-maternal death.

For an extensive discussion of this new thinking on population, see Finkle and McIntosh, (1994:3).

This information on the history of demographic planning and control in Sri Lanka was presented at a Seminar on "Population Trends and Issues in Sri Lanka," by ATPL Abeykoon, Director, Population Division, Ministry of Health, on 23 February, 2001, at the Faculty of Arts, University of Peradeniya. Division, Ministry of Health (2001) at the Seminar on "Population 
Trends" (see Note 8 above) on the Ministry's response to the (reportedly high) incidence of abortion in Sri Lanka, he first disputed the (high) numbers and then asserted that the Ministry relies on "promotion of family planning," not abortion, for population control. He refused to be drawn on the question of whether abortion should be legalized in Sri Lanka.

Both Hewage (1994:322) and Sirisena (1991:1) claim complications arising from abortion to be one of the leading causes of maternal death in Sri Lanka although neither gives specific figures to support their assertion.

The Letter of Government, Issue No. 4, 21 September 1999, published by the Policy Research and Information Unit of the Presidential Secretariat.

For more information on their thoughts and positions on this issue, see Goonasekere in "Asian Values, Equity, and a Sri Lankan Family Policy" (2002:6), Jayawardena \& de Alwis in "The Contingent Politics of the Women's Movement in Sri Lanka after Independence" (1997:273) and Sunila Abeyesekera in "Abortion in Sri Lanka in the Context of Women's Human Rights" (1997:92).

See Tribe (1992:10-14) for a succinct account of the judicial decision in Roe $v$ Wade.

See Poovey (1992:239-40) and Frances Olson (1989:3).

According to Sunila Abeyesekera, "legislative enactment is the only available method of modifying the Penal Code" (1997:88).

The Sri Lankan newspaper, The Sunday Leader, 27 February 2000, carried a news items about a 10-year old girl (sexually molested and impregnated by her mother's lover) who, at 11 years of age, is the mother of a 3 -month old infant. Legalized abortion would have helped prevent the suffering of such child mothers. 
In $1994,73 \%$ of the temporary migrant workers were female according to Malsiri Dias and Nedra Weerakoon, in "Migrant Women as Domestic Workers from Sri Lanka: Trends and Issues," (1995:200). More than half of this number is reportedly married, but undertake the journey in hopes of bettering the economic lot of their families.

According to one study conducted among Export Processing Zone workers, $98 \%$ of the women workers were single and $96 \%$ were below 30 years of age (Goonatillake \& Goonasekere, "Industrialization of Women Workers in Sri Lanka: Working Conditions Inside and Outside the Investment Promotion Zones," (1988:190). This suggests that there are no incentives for women workers in such jobs to stay on after marriage.

The 1992 G.C.E.C. figures for employment rates indicate that $58.9 \%$ of skilled workers, $90.8 \%$ of semi-skilled workers and $72.9 \%$ of unskilled workers in G.C.E.C. industries are female (Source: Swarna Jayaweera, “Women and Employment," 1995:177).

See the companion volumes, Thiruchandran's The Other Victims of War, and Sasanka Perera's Stories of Survivors, for insightful analyses of this phenomenon.

In the United States, extremist Pro-Life groups have gone to the extent of protesting outside of and blocking access to known abortion clinics, holding placards up and screaming "baby-killers" at service-seekers and -providers coming to the clinics, firebombing/vandalizing some such clinics, harassing service providers at home through the mail and phone lines and, in 1994, killing a medical practitioner. The famous American Pro-Life film based on an actual abortion procedure titled The Silent Scream is acknowledged by many to be very potent in these groups' crusade against legalized abortion. For a detailed account of the modus operandi adopted by the Pro-Life coalition in the US, see Tribe, 1992:171-72. 
22 For an incisive analysis, see Catherine MacKinnon, 1987:32-46.

In the United States, fundamentalist Christian groups have now taken the lead in the fight against liberal abortion laws and its practice (Crane, 1994:248).

For an illuminating account of the transnational coalition against abortion, see Crane, 1994:241-62.

Founded in Britain in 1970, Marie Stopes International, named after an early twentieth century birth-control counselor and activist, "assists family planning clinics in some South Asian and African countries in the areas of abortion and contraception" (Crane, 1994:250).

From a medical point of view, abortion, performed in early pregnancy is a relatively simple and safe procedure if done within a hygienic environment using the proper tools, with the latest medical know-how, by trained personnel (Crane, 1994:249). What makes the procedure unsafe is its criminalization, which drives the practice underground and into the hands of people who perform the procedure mostly with profits in mind.

For a history of the "global gag rule," see Crane, (1994:241-62). For a local feminist coalition's response to the re-imposition of the rule, see Cat's Eye.

Finkle and McIntosh in fact argue that feminist groups the world over need to take more interest in family planning policy decisions and attempt to influence the design and implementation of population programmes because these have a direct impact on the reproductive well-being of women. Since foreign donors decide which contraceptives to subsidize and to be made available in developing countries and which types of providers to support, Finkle and McIntosh propose that activists from the developed and developing worlds come together in transnational coalitions 
to influence international and national policy agendas when it comes to such matters ("The New Politics of Population," 1994:24).

Two teledramas currently playing on Rupavahini, Sanasili Suvanda and Derana, in their episodes aired on 19 March 2002 and 9 March 2002, respectively, demonize abortion service providers. In Sanasili Suvanda, the arrogant brother's son-inlaw claims to be a "doctor," but turns out not to be and is referred to as a "hora dhosthara" or quack whose forte is abortion. In Derana, a young village lass seduced by the elite lover with promises of marriage resorts to help from an indigenous villagelevel quack, a woman, when she finds herself pregnant but ends up dead from a botched abortion. In both, a link is being made between quackery and abortion - that it is performed by people who are dishonest and callous.

30 The legislation proposed, and then dropped, in 1995, required that abortions be carried out in state hospitals and registered nursing homes only (Abeyesekera, 1997:88).

\section{References}

Abeyesekera, Sunila. (1997) "Abortion in Sri Lanka in the Context of Women's Human Rights." Reproductive Health Matters. 9 May: pp. 8793.

Ariyaratne, Vinya \& Richard S Brooks. (2001) "An Integrated Approach to Reproductive Health: The Sarvodaya Experience." Sri Lanka Journal of Population Studies. 4 March: pp. 41-52.

Berer, Marge. (1997) “Abortion: Unfinished Business." Reproductive Health Matters. 9 May: pp. 6-9.

Cat's Eye. (2001) “Bush Turns Right." The Island. 15 February: p. 11. 
Coomaraswamy, Radhika. (1988) "The Impact of 'Tradition, Culture and Religion on Women in South Asia." Ethnic Studies Report. 6.2 (July): pp. 65-92.

-. (1991) "Of Kali Born: Women, Violence and the Law." Seminar on Women \& Violence. 9 March. Kandy: ICES. pp. 1-15.

Cornell, Drucilla. (1992) "Gender, Sex, and Equivalent Rights." Feminists Theorize the Political. Judith Butler \& Joan W Scott (eds.) New York: Routledge. pp. 280-96.

Crane, Barbara B. (1994) "The Transnational Politics of Abortion." The New Politics of Population. Jason L Finkle \& Alison McIntosh (eds.) New York: The Population Council. pp. 241-62.

de Silva, Soma. (2001) "Maternal Mortality in Sri Lanka: Estimation, Levels, Trends and Issues." Sri Lanka Journal of Population Studies. 4 March: pp. 49-65.

Dias, Malsiri \& Nedra Weerakoon. (1995) "Migrant Women as Domestic Workers from Sri Lanka: Trends and Issues." Facets of Change. Colombo: CENWOR. pp. 195-228.

Dimock, Wai-chee. (1990) "Rightful Subjectivity." Yale Journal of Criticism. 4 (1): pp. 30-42.

Dworkin, Ronald. (1989) "The Future of Abortion." New York Review of Books. 28 September: pp. 39-51.

—. (1989) "The Great Abortion Case." New York Review of Books. 29 June: pp. 49-53.

Finkle, Jason L \& C. Allison McIntosh. (1994) "The New Politics of Population." The New Politics of Population. Jason L Finkle \& Allison McIntosh (eds.) New York: The Population Council. pp. 3-34. 
Goonasekere, Savitri. (1996) "Asian Values, Equity, and a Sri Lankan Family Policy." GC Mendis Memorial Lecture. Colombo: n.p. pp. 1-21.

Goonetillake, Hema \& Savitri Goonasekere. (1988) "Industrialization of Women Workers in Sri Lanka: Working Conditions in and Outside the Investment Promotion Zones." Daughters of Industry: Work Skills and Consciousness of Women Workers in Asia. Noeleen Heyzer (ed.). Kuala Lumpur: APDC. pp. 184-209.

Gupte, Manisha, Sunita Bandewar \& Hemlata Pisal. (1997) "Abortion Needs of Women in India: A Case Study of Rural Maharashtra." Reproductive Health Matters. 9 May: pp. 29-35.

Hewage, P. (1994) "Induced Abortion in Sri Lanka: Opinions of Reproductive Health Care Providers." Abortion in the Developing World. Axel Mundigo \& Cynthia Ingram (eds.)New Delhi: Vistaar. pp. 321-34.

Jayawardena, Kumari \& Malathi de Alwis. (2002) "The Contingent Politics of the Women's Movement in Sri Lanka after Independence." Women in Post-Independence Sri Lanka. Swarna Jayaweera (ed.). Colombo: Vijitha Yapa. pp. 245-81.

Jayaweera, Swarna. (1995) "Women and Employment." Facets of Change. Colombo: CENWOR. pp. 156-94.

MacKinnon, Catherine. (1987) "Introduction: The Art of the Impossible." Feminism Unmodified: Discourses on Life and Law. Cambridge, MA: Harvard University Press. pp. 1-57.

Minow, Martha. (1987) "Interpreting Rights: An Essay for Robert Cover." Yale Law Journal. July: pp. 19-46.

—. (1987) "Justice Engendered." Harvard Law Review. November: pp. $30-44$

Olsen, Frances. (1989) "Unraveling Compromise." Harvard Law Review. November: pp. 10-24. 
Perera, Sasanka. (1998) Stories of Survivors. Colombo: WERC.

Petchesky, Rosalind. (1990) Abortion and Woman's Choice: The State, Sexuality, \& Reproductive Freedom. Boston: Northeastern University Press.

Poovey, Mary. (1992) "The Abortion Question and the Death of Man." Feminists Theorize the Political. Judith Butler \& Joan W. Scot (eds.). New York: Routledge. pp. 239-56.

Rance, Susanna. (1997) "Safe Motherhood, Unsafe Abortion: A Reflection on the Impact of Discourse." Reproductive Health Matters. 9 May: pp. 10-19.

Samarasinghe, Daya. (2002) “Women's Health, Population and Quality of Life." Women in Post-Independence Sri Lanka. Swarna Jayaweera (ed.). Colombo: Vijitha Yapa. pp. 143-211.

Sirisena, Jayantha. (1991) "Abortion and Rape: A Medical View." Seminar on Women \& Violence. 9 March. Kandy: ICES. pp. 1-12.

Thiruchandran, Selvy. (1998) The Other Victims of War. Colombo: WERC.

Tribe, Lawrence. (1992) Abortion: The Clash of Absolutes. New York: Norton. 